\title{
OBSESSIVE-COMPULSIVE STATES IN CHILDHOOD AND THEIR TREATMENT
}

\author{
By MURIEI، BARTON HALL, M.D.
}

(Honorary Physician, Liverpool Psychiatric Clinic; Honorary Medical Psychologist, Liverpool Child Guidance Clinic.)

The object of this paper is to discuss a problem with which consultant and general practitioner are alike faced, and to deal with the subject from the standpoint of general medicine in language from which, so far as possible, the more advanced psychological terminology has been eliminated. When it is realized that, failing correct and adequate treatment, compulsive states may persist throughout life, the importance of their recognition and treatment in childhood need hardly be stressed. It is not perhaps generally known that the cure of the obsessive states of childhood is cne of the most satisfying, and even dramatic, things in medicine; cne of the too few instances in which psychological treatment apprcaches the realms of an exact science. Arising, as they do, from fear and uncertainty, mild, fleeting compulsive acts are relatively common in childhood and respond readily to simple reassurance or to explanations which unde:mine the child's fears and satisfy his doubts. From time to time, however, the aid of the practitioner is sought in cases of obsessivecompulsive neuroses which are of such intensity and permanence that the child is not only prevented from attending school or associating with other children, but is the despair of his parents, who, as daily observers of what appear to them to be unnecessary and meaningless repetitions and ceremonials, cannot ccnceal their disapproval or refrain from outspoken criticism of his behaviour.

\section{Aetiology.}

In the majority of cases there is a psychopathic family history, and parents will often describe similar symptoms which occurred in their own childhood and which are attributed by them to a sensitive, worrying and over-conscientious nature. Boys and girls are affected with equal frequency. Symptoms may show themselves so soon as the child is old enough to associate freely with other children and may make their first appearance at any time during school days. The child so affected is invariably sensitive, timid, imaginative by nature, with a fully-developed moral sense. The degree of development in general intelligence does not appear to be a contributing factor in that both the dull and the highly intelligent child may suffer equally. A characteristic feature of the personality make-up of such patients appears to be the ease and readiness with which they are able to express themselves in writing whether it be in prose or in verse. 


\section{Symptoms.}

The condition is best portrayed by description of actual clinical cases; two typical examples are therefore given in some detail for purpose of illustration.

A., a girl, aged twelve and a half years, was the elder of two children of artisan parents, the younger child being a boy. Her birth was instrumental and was followed by convulsions during the first few days of life, after which development and health were normal until she was four and a half years old. About this time the girl developed peculiarities which were diagnosed as chorea. She would stop suddenly in the street and put her hands above her head. She would knock her hands against her chest until she was bruised. She would make peculiar grunting sounds. She became hysterical, cried if she was spoken to, screamed if she could not have her own way. These symptoms persisted continuously for eight years in spite of long periods of residence in hospital and of convalescent treatment. During the twelve months prior to her first attendance the symptoms had become gradually more pronounced. The patient had bouts of hysterical sobbing and screaming, was sensitive to correction, had attacks of enforced activity during which she was compelled to skip every third step in walking, or do what her mother called ' a bit of a step-dance,' to cough repeatedly, to sneeze violently, make grunting sounds or repeat obscene words and phrases. These forms of activity became more pronounced at night and prevented the girl from obtaining sleep until the early hours of the morning. She would repeat some phrase such as 'good-night' or what her mother described as ' the back end of a scream,' a thousand times until she fell asleep exhausted. Her state was one of chronic excitement. She could keep no information to herself. If she heard news or gossip in the street she was compelled to run home immediately and repeat it to her mother. If she saw a person spit or blow their nose she felt compelled not only to do likewise but to repeat the action a score of times. When indoors she could not sit still, was continually shouting and kept turning the gas taps off and on. Out of doors she continually stopped in the street in order to skip a step before proceeding on her way. Anything that came into her mind had immediately to be repeated. So bad had her condition become that the parents dare not travel with her in a public vehicle for fear of what she might say or do. She had been unable to attend school for three months, and prior to this had attended only at irregular intervals. Her condition was becoming steadily worse and had culminated in a liability to speak of her developing body in her father's presence with no sense of shame or modesty.

On examination there were no physical signs of chorea or of other organic disease. She was a good-looking, intelligent girl (mental age fourteen years and one month, I.Q. 113) with flushed face, active mind and body and an outspoken manner. The emotional instability described by the parents was revealed in the initial examination, together with the grunts and sneezes which were interjected in her conversation. The girl's feeling 
of hopelessness with regard to her condition was summed up in her first words when, on interviewing her in the absence of her parents, she broke out into hysterical weeping and moaned, 'I hate doctors. Why wasn't I made like other girls? Everywhere I've been they've half cured me and turned me out. I'm fed up with it all. Life's not worth living.' After this storm was over, the patient went on to explain that she felt compelled to imitate everything she saw or heard, no matter how vulgar. If she was occupied she could manage to forget her illness, but so soon as her mind was unoccupied for a single minute, as for example in bed at night, it was immediately full of swear words and unclean words that she felt forced to repeat. When she stopped in walking, sneezed, coughed, or screamed, she knew that these actions were mere substitutes for indecent verbal expressions. The patient could remember that she had suffered from similar symptoms since she was six years of age.

B., a boy, aged twelve and a half years, was the second child of respectable working-class parents, his elder brother being seventeen years his senior. When he was six years of age, shortly after he began to attend the local elementary school, he ran in from his play in the street with other boys and stated that he thought he was going to die. On enquiry, his mother found that his playmates had frightened him by telling him things that he had not understood. She reassured him and told him to take little notice of the boys. From this time on he began to change in his manner. From a lively, care-free child he became one who worried constantly about his health and was in daily dread of appendicitis, blood-poisoning, or any other illness which he knew might have a fatal termination. He would not leave his mother's side, refused to play with his school-mates and could not be induced to attend school. His sleep was disturbed by nightmares. He suffered from sensations of collapse during which he felt that his feet would go from under him. At these times the colour left his face, he looked physically ill, he vomited and complained of headache and of tiredness. His symptoms varied in intensity from day to day, but he was never quite normal. His school attendance amounted to no more than two and a half years over a period of six years. When he was eleven years of age, while spending a holiday with some relatives in the country, and sharing a tent with another boy, he was suddenly seized with acute panic and was certain he was about to die. Following this he was noticed to develop a number of habits. For example, he began to touch things twice, to be over-scrupulous about washing his hands, kept going back to see that the tap was turned off, that the door was properly closed. He became fussy about passing water, felt that he must keep going to the lavatory. He was irritable in temper, difficult to please, he found fault with everybody and everything, was sensitive to correction, could not sit still in school and in church or in a place of amusement he would want to jump up and rush out. He was a constant source of anxiety to his parents, not only on account of his behaviour and moodiness, but because he was unable to attend school and showed no promise of being able to retain employment on reaching school-leaving age. 
On examination, there was no sign of organic affection. He was an intelligent boy (mental age fourteen years and three months, I.Q. 114), of quiet, reserved manner, displaying outwardly none of the tendencies which had been described by his parents, but the appearance of his eyes and his facial expression spelt anxiety and nervous exhaustion. The boy, describing his own symptoms, explained how the battle between his impulses and his efforts to control them was so severe that it seemed to take all the energy out of him. He described bouts of vomiting, attacks of excessive appetite, frequency of micturition, pains all over the body, heavy feelings as though he could hardly drag one leg after another. He described a heavy, dull feeling in his head, attacks when everything seemed to go black, difficulty in thinking and concentrating. Every pain or sensation suggested some serious disorder. He felt that he would die and go to hell. He was worried because he was not religious enough. He was afraid that he might become a thief, had to keep saying prayers. He felt that he must say his prayers very slowly, and in his effort to prolong them, found that he stammered over the amen. He could not do anything without first being reassured by his mother that no harm wou'd come to him. He kept apologizing to her for errors he had not committed. There were certain chairs that he felt he must not sit on, others he had to tip up, or blow the dust from before he sat down, and spots where he dare not stand. On attempting to read he could not begin a new chapter, a new page, a new line. He felt that it would be a sin to omit to comply with these forces, and to resist them was like trying to put his hand into scalding water. He dreamt of red devils, black boxes, coffins, and of being swept along the street with the refuse. He had pictures of Jesus in his mind which he could not remove. He had to keep pressing his thumbs together, keep breathing out, keep praying. His life was a nightmare.

Although the cases are similar in their general conformation, each seems to have its own particular characteristic. It seems, too, from the cases investigated and treated by the writer, that the actual form of the symptoms depends to a certain extent on the temperament of the patient. The child who is of extraverted temperament, as for example the first case described in this paper, who is warm-hearted, sociable, and an expender of energy, very much in touch with the world, a talker, is apt to develop a form of obsessive neurosis which may necessitate the forceful repetition of obscene words or actions. These are abruptly disallowed by the parents, and are substituted by grunts, sneezes, or other sounds more acceptable to the public. When the child is alone, however, as in bed at night, the active repetition of the forbidden word or phrase is heard in its full force. In the child of introverted temperament, on the other hand, the child who is less sociable, not so closely in touch with his fellows, more secretive, an energy conserver, of which the second case in this paper is a good example, the symptoms take a less violent or energetic form. The compulsions are limited to thoughts and stereotyped actions and ceremonials associated with every-day activities, such as washing, dressing, eating, etc. 
The onset of the disorder is often insidious, the patient concealing from his relatives for many months the thoughts and actions by which he is obsessed. The parent usually considers that the symptoms date from an accident, a fall, a shock, etc., but an interview with the patient shows that they had antedated the supposed shock by many months and only became evident at that time on account of lowered resistance and less adequate nervous control. The majority of cases have shown symptoms for from two to five years before being sent for investigation and treatment. The parents at first think the child eccentric and make allowances for what they consider to be his peculiarities, but when the symptoms begin to interfere seriously with school attendance and show a likelihood of preventing the adolescent's entrance into the labour market, some definite step is taken to obtain advice.

It will be seen from the clinical cases that the symptoms are protean in number but that they fall into two main groups of subjective and objective, the subjective being the predominant ones. Of the mental symptoms, irritability of temper, emotional instability, obsessions, insomnia, fatigue, excitability, depression and inability to concentrate are the commonest, while physically, cardiac disturbances with palpitation and breathlessness, respiratory symptoms, more particularly feelings of suffocation and sighing, profuse sweating, tremors, paraesthesia, dizziness, disturbance of appetite and of bowel action and loss of body weight may be present. It will, of course, be apparent, as in all neuroses, that symptoms may be referred to any area or organ of the body.

\section{Diagnosis.}

The diagnosis of such cases is straightforward. A clear account of the history of the symptoms can usually be obtained from the parents, while the child has little difficulty in giving an account of his thoughts and feelings in that they are so real in their manifestations. The gradual onset of fear of unknown origin with the later development of obsessive acts and the accompanying symptoms of nervous exhaustion are typical. In those cases in which twitching movements, e.g., of the head and shoulders, skipping gait, tendency to kick the buttock with the heel of one foot every few steps, etc., are the predominant symptoms, a diagnosis of chorea has sometimes been made, but careful observation of the patient will reveal these as purposive and not involuntary movements, in that they are substituting the repressed thought or impulse. In a case in which the impulse to skip at every third step was firmly handled, this symptom vanished, but was replaced by a high-pitched squeak at similar intervals.

A possible, if infrequent, source of error in diagnosis is that of the mild manic-depressive state or cyclothymia. It is perhaps not commonly realized that these states may be observed in childhood, but such cases are of occasional occurrence in the experience of the psychiatrist. They are characterized by the usual symptoms of psychomotor over-activity, 
insomnia, emotional instability and exhaustion. Dreads and obsessive acts, simulating obsessive compulsive states, may also occur. These are, however, fleeting, of no constant significance, and tend to clear up completely in the normal course of recovery within two or three months from onset of the disease.

Possibly the greatest difficulty in differential diagnosis, more particularly in cases of long-standing, is that of dementia praecox in its earliest stages. The real difference lies in the complete insight into his condition which the child with obsessive neurosis retains. Although he does not understand the cause of his symptoms, he realizes that they are odd, and can, to a certain extent, exert control over them. With the case of dementia praecox, on the other hand, although the child realizes in the early stages that some change has taken place in his thoughts and behaviour, and that his actions are peculiar, when urged to discuss his thoughts and feelings, his interpretation of these reveals mild, illusional, delusional and hallucinatory states, as, for example, the case of the boy who felt that he must look at everything he saw twice, when asked why this was necessary said, 'Because it changes into God, and it would be a sin to turn away from Him.' In conversation, too, the observer will be struck by the extreme normality of approach in the case of the neurotic as compared with the unreal and abnormal attitude and approach of the psychotic.

Another problem in differential diagnosis is presented by the illness known as maladie des tics (Gilles de la Tourette). What have usually been regarded as the pathognomonic features of this condition, notably stereotyped movements in face, neck, upper and lower extremities, beginning in the face and extending to the rest of the body, echolalia, coprolalia, compulsive ideas and gestures, are all present in many cases of the type under description. This might point to a psychogenic explanation to account for maladie des tics, but the problem is further complicated by the fact that the syndrome may appear during the course of certain organic affections such as epidemic encephalitis. It would seem, therefore, that the only point of differentiation can be whether or not the case responds to psychological investigation and treatment, an admittedly weak position. This instance at any rate serves to emphasize the difficulty, frequently experienced, of drawing a line of demarcation between conditions which have been distinguished as either 'functional' or ' organic.'

\section{Prognosis.}

The outlook for recovery in cases of obsessive neurosis should be favourable if adequately handled during the developing years. It is sometimes asserted that obsessive-compulsive states tend to clear up in the ordinary course of events and that they therefore do not merit serious psychological understanding. In my view such an impression is unfortunate in that it frequently results in the case never being properly dealt 
with and in the condition continuing with remissions and exacerbations, intermittently, and varying in intensity with the stresses and strains of human existence, throughout life. Moreover, however successful may be the result of treatment undertaken when the patient has reached young adult life, the process of such treatment is infinitely more difficult, complicated and prolonged than in childhood.

The most helpful adjunct to treatment is good, intellectual development in the patient, more particularly as regards powers of reasoning and application, in that the solution of the problem and disappearance of symptoms is dependent upon the patient's ability to discover and discuss those thoughts and experiences in his life which have been repressed through fear, shame and uncertainty, and have been acting as irritants of which the symptoms already described are the outward and more respectable manifestations.

Treatment.

To understand the mode of production of such disorders is to know how to handle them, and for that reason it is thought desirable to deal with the psychopathology of obsessive neurosis, before discussing management of the case and the method and technique of treatment.

(a) Psychopathology. - Although the disorder of obsessive neurosis presents so puzzling a group of symptoms on the surface, its origin is of comparatively simple foundation. The disorder may be summed up as the result of certain experiences acting upon the subconscious minds of certain predisposed personalities. A child who is by nature timid, lacking in confidence, sensitive to criticism, and who is over-conscientious in that he sets an unduly high standard of morals for himself and for others, comes in touch, for the first time, either at school or in the streets, with a more robust make of child to whom the facts of coitus, pregnancy and childbirth, among other information, are common knowledge. $\mathrm{He}$ sees, hears discussed, and becomes aware of the existence of such matters for the first time, but in such a way that his sensitive nature revolts and refuses to accept them. The instinctive curiosity born of his own half-awakened sexual impulses does not allow him to forget the incidents and facts. Thus, his mind is involved in a difficult conflict. On the one hand stand his moral standards, often taking dramatic form in an imaginative child who carries in his mind vivid mental pictures of religious punishments, disease and death. On the other hand, he is urged forward by his tardily developing instinctive trends. The latter are not sufficiently forcible to declare themselves so openly as in his more robust fellows; they therefore only express themselves behind a screen of behaviour to which no exception can be taken. Thus an endless succession of ceremonial acts based on scruples of apparently hygienic or religious significance become substitutes for the thoughts and acts which are abhorrent to the timid mind. The inevitable 
result of this intra-psychic conflict is the characteristic anxiety state and its accompanying nervous manifestations.

Sexual experiences are common in childhood. A boy may indulge in sexual play with his sister or with a neighbour's child in a rigged-up tent. Although he realizes that such behaviour would not be admitted by adults, his sense of guilt is not stirred until he learns something of the significance of the function of the male and female sex organs. The fact that he obtains this knowledge from those who have but scant information themselves, but information of the grossest, crudest, most primitive kind, renders what might be a clean, wholesome and shameless explanation of these mysteries, a veritable nightmare of possibility.

(b) Method.-The first aim of treatment must be that of helping the child to unload his mind of those doubts and uncertainties which are molesting him. This process is easy in theory, yet, in practice, is beset with many difficulties. The average length of time required for recovery will be six months, the actual duration being dependent upon the length of the illness on the one hand and the readiness with which the child's confidence can be gained on the other. To most parents the idea of a six months' course of treatment is not a disadvantage in comparison with the years of anxiety that they have already endured. As in all children's work, there are always two persons to be considered in treatment, namely the child and his guardian. The parent must be willing to leave the case entirely in the hands of the doctor and only to act in exact accordance with his instructions. The parent must be given to understand that the treatment will be lengthy, but that an ultimate cure will result. He must give his consent for the child to be interviewed by the doctor alone and must promise not to question the child as to what occurs between patient and doctor. Should the child himself discuss the interviews the parent should be taught to refrain from criticism or comment, but to show by his attitude that he understands the situation and has faith in the ultimate outcome of the treatment. The parents must also be warned that there will be an exaggeration of the symptoms and increased irritability of temper and of general restlessness during the first few weeks of the treatment as this invariably happens and is apt to cause undue anxiety and distress to those in the home unless they have been previously warned. During the time that treatment is being undertaken, the child should not attend school, or be encouraged to indulge in any activities which require more effort than he can spare with ease. A quiet life in his own home with those who understand him is the ideal to be aimed at in the early stages of treatment.

With regard to the patient, his confidence must be gained by degrees. At first he will be suspicious; he has become so accustomed to such remarks as 'stuff and nonsense,' ' all your imagination,' ' you must learn to fight it,' in response to a recital of his symptoms, that he cannot conceive that they might be listened to with interest, nor that 
anyone could really understand the effect that they have upon him. In my own experience of children under fourteen years of age, two visits a week each of thirty to forty-five minutes' duration is adequate time to devote to treatment. After physical factors have been excluded, the first interview alone with the child should give him an opportunity of describing his symptoms in detail. He should be encouraged to do this by such remarks as ' anything else you feel,' etc., until he realizes that you are truly interested in his case. The first interview may be terminated by telling him that you have known other boy and girl patients with just his trouble and that if he does what you ask of him there is no reason why he should not make a complete recovery just as they did. One never ceases to be amazed by the relief which follows the realization by the patient that other children have existed in whom the urge to count, to wash their hands, etc., has been present.

At the second interview, the patient should be given an opportunity of telling those things which he forgot to tell at the first interview. If you have gained his confidence he will have much to add. Much that he says may not appear to be relevant, as for instance the information given by a boy in the early stages of treatment, with a good deal of hesitation, that he had been told that if you picked a certain flower your mother would die. This remark seemed to have little significance until a later stage in treatment when it was discovered that he had derived information regarding the nature and risks of childbirth from the same source. At the end of the second interview it should be possible to begin to explain to the patient the facts with regard to the working of the subconscious mind. The idea of a deep mind and a superficial, or outside, mind with a constant conflict or battle between the two over something that is buried in the deep mind is readily understood by the average school child, but is particularly well understood by children suffering from obsessions in that their former vague symptoms now appear logical and the patient himself will find it possible to give evidence of the actual states of repression and conflict.

At this stage the patient will realize that you understand the nature of his case and will begin to fear that you will discover his innermost secret. It is this fear and the consequent increased conscious effort to retain the required information that causes an increase of the obsessions and of the general irritability of temper. Because there is a certain amount of strain resultant from treatment at this stage, it is wise to avoid hurrying the process. No element of cross-examination should enter in, but the patient should be allowed time to adapt slowly to the new attitude towards his symptoms. Be sure that the patient understands the way in which treatment is going to bring about a cure. Get him to suppose that he has been asked by his relatives how it works, and in this way you can be certain whether he really understands the process or not. At this stage he becomes really interested in his case and its solution, and this forms an inducement for him to tell you more of his 
thoughts and experiences. Ask him about his dreams. At this stage of treatment they will be of great significance. He may tell you that he dreamt he came to see you and that you held a closed book in your hand which you opened to show him the clean leaves inside. Ask him what he thinks it means and he will tell you, if he has become used to thinking aloud in your presence, that you will explain things to him which have previously been a closed book to him. He may dream that he has been an inmate of a reformatory for a year but has obtained his release on good conduct before his time was up, explaining that the dream was an indication of his gradual return to normal standards of thought and behaviour. Guard against trying to extract a coherent life history from the patient. Allow him rather to tell his own story at his own pace.

If all goes well, after several weeks, the child will come to you slightly excited, and will blurt out some fact or tell you that he intends to get something off his chest before the end of the interview. He may weep, sob, laugh, or remain calm, as he informs you of the facts. It is important to remain detached in mind and unaffected by what he is trying to tell you. Allow him adequate time. Remember it is the telling that matters and not the material that is told. It must, of necessity, be something of a sexual or allied nature in that this is one of the few subjects on which he cannot approach his parents. He will describe events which were of no significance to him at the time they occurred except that he knew them to be wrong, but he will go on to explain that it was what he saw and heard at a later date that made him worry about the previous incidents.

From the moment of his confession, the obsessions will show definite improvement, but there are still weeks of difficulty ahead before they vanish completely. The child now wants to know the truth of the information that has been imparted to him by his undesirable associates. It is a great temptation at this stage to give the required sex information and to enquire in what way the truth differs from the facts as he first heard them, but to do so would be a gross error of judgment. He must tell you of the ideas he already holds with regard to these matters before you explain them to him; otherwise there may be fallacies in his knowledge which are not cleared up. Several more weeks may elapse, during which time it is important to make certain that he realizes that although he is now so very much better in that he can eat, sleep, play with other boys, only by dealing with every single doubt and uncertainty in his mind can he feel completely free. Finally the day will come when he has sufficient courage to repeat some of the things he has seen and heard, but has not understood. Once this ice is broken there is no looking back. He becomes the happy, care-free, contented child he was described to be by his parents before the onset of his illness. It may seem strange that it should take some months to obtain the information, the getting of which is so vital to the cure of the case, but these are invariably ambitious young people whose very self-respect acts as a deterrent in their attempts at full confession. How far the child's conscious mind is 
aware of the cause of the trouble in the early stages of treatment varies with the individual case, but one boy described a ' blackness' that gave him a headache when he first began to think about the cause of his obsessions, which gradually became less dense and no longer associated with pain in the head as he arrived nearer to the cause of his trouble.

In cases in which there appears to be an obstinate refusal to delve into the origin of the disorder, it may be legitimate to introduce information received from other children as examples for his encouragement or to explain the meaning of his symptoms, such as, for instance, hand-washing as a symbol of an attempt to remove some blemish or stain from the mind. This may give the patient renewed confidence in your understanding of the case and make him feel that he is not the only one who has experienced such thoughts and acts, and so enable him to progress at a faster rate. On the whole, however, so long as the parents are satisfied. it is wiser to allow the case to take its own course. In young people, a return to school after a period of six months of treatment should be possible in practically every case.

It is impossible to give, in a paper such as this, every likely symptom, cause and eventuality in treatment, but an understanding of the nature of the disorder and of the methods required to bring about an adjustment, brings the treatment of obsessive-compulsive states in children within the range of the practitioner who has sufficient time to devote to such cases. 


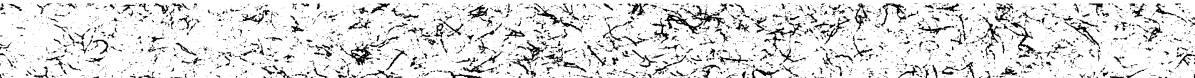

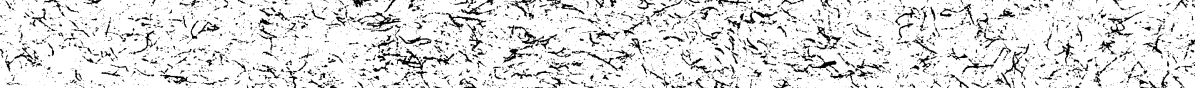

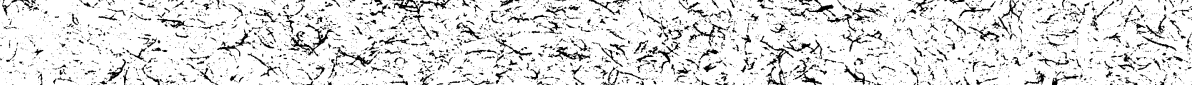

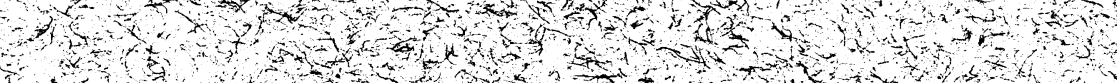

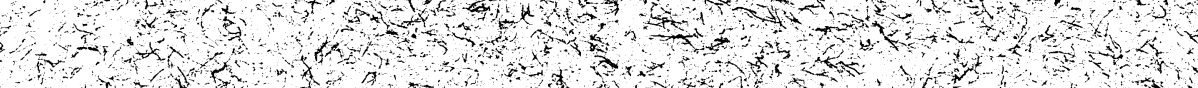

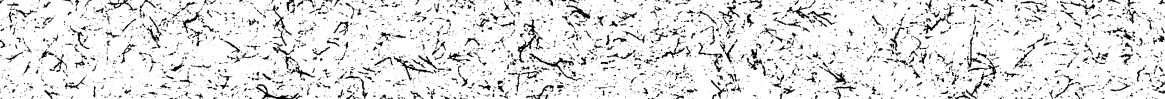

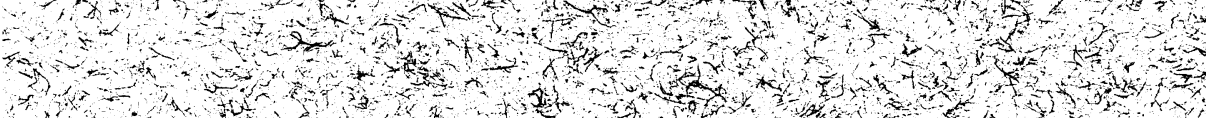

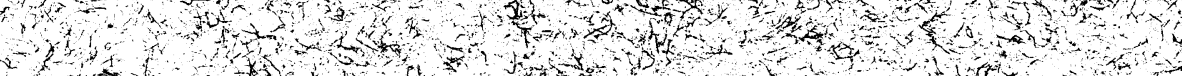

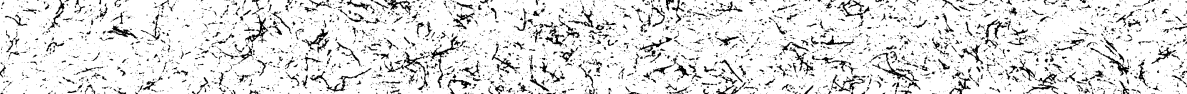

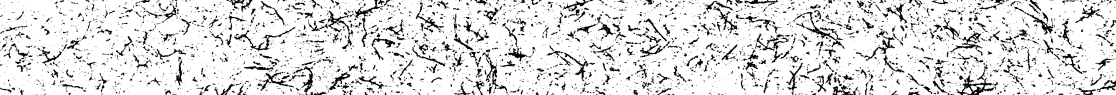

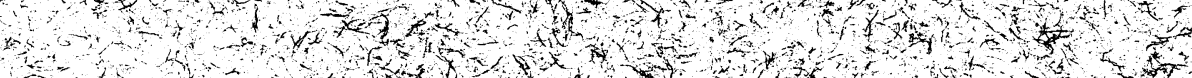

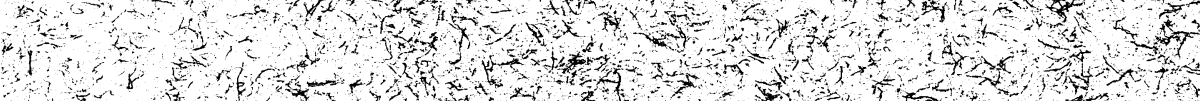

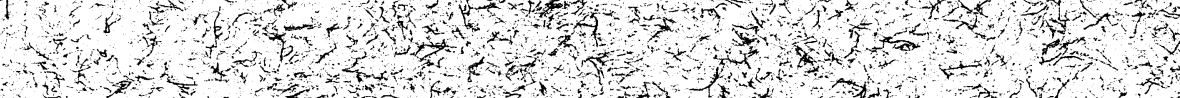

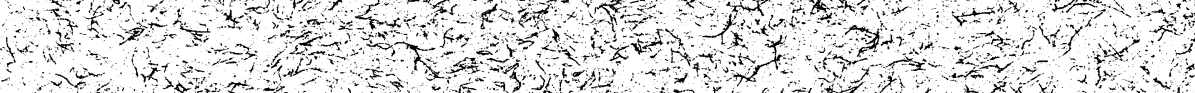

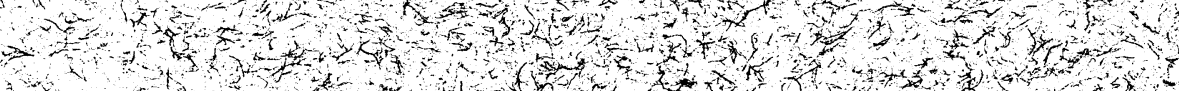

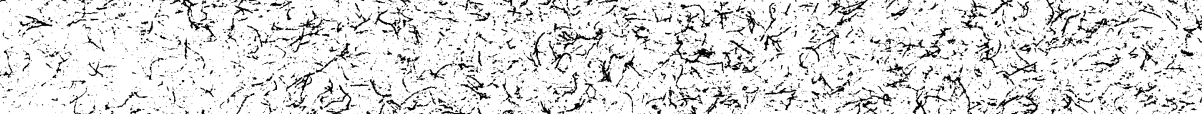

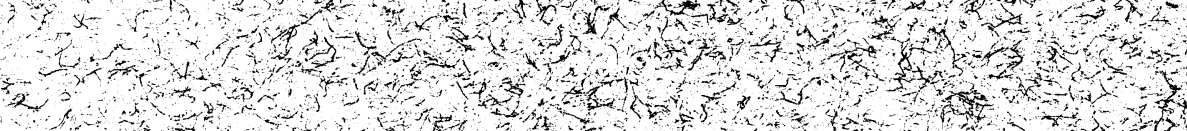

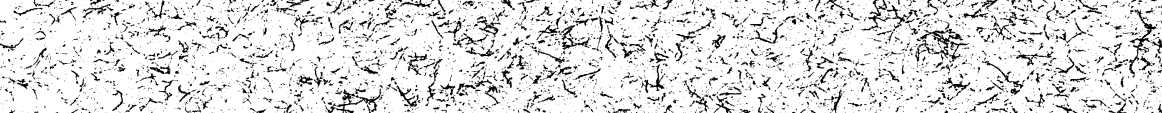

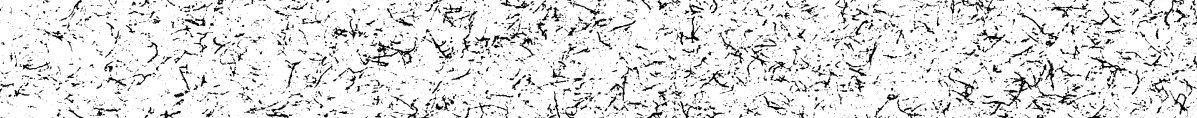

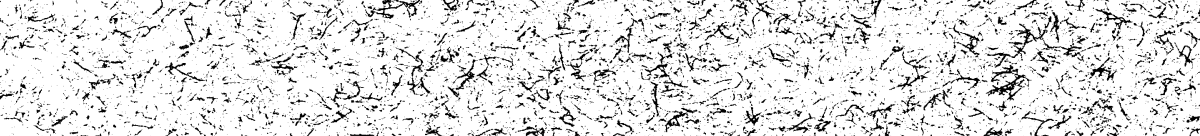

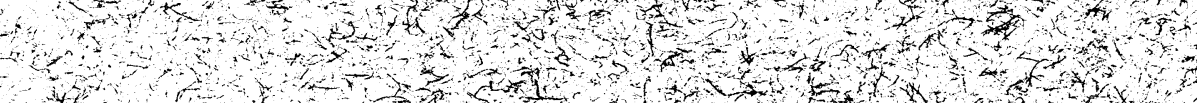

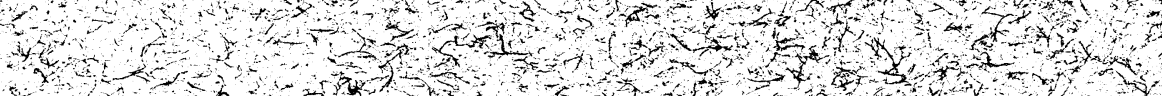

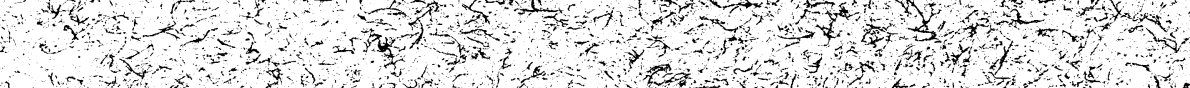

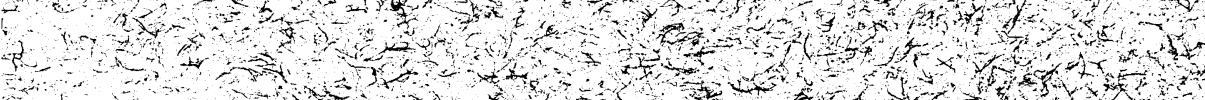

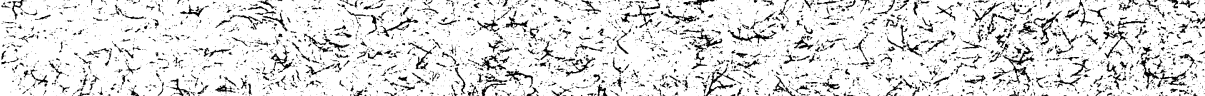

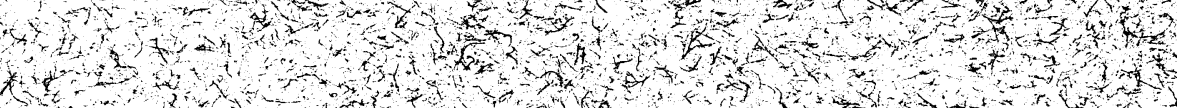

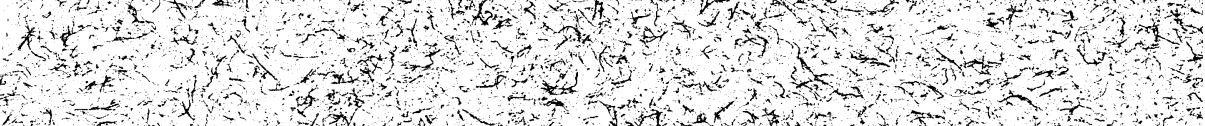

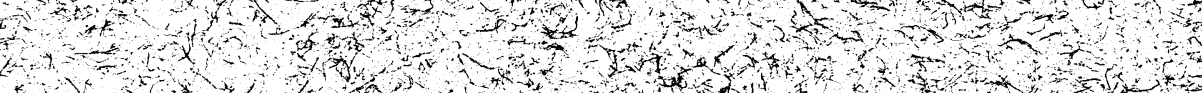

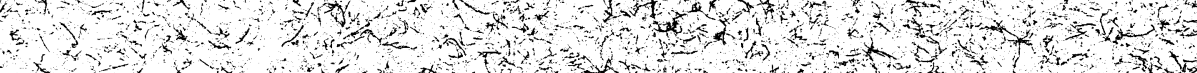

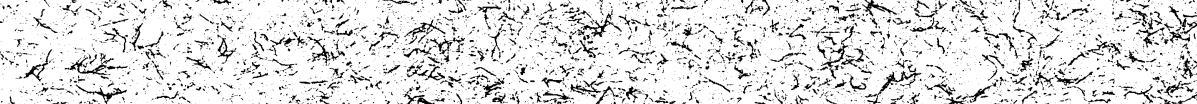

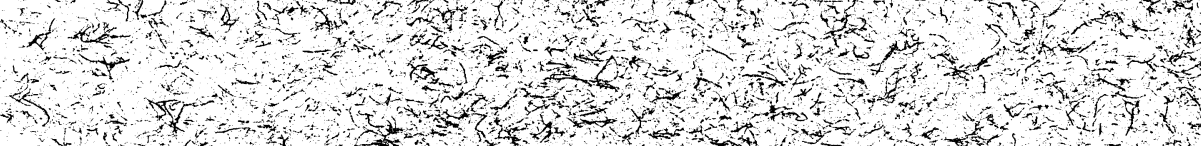

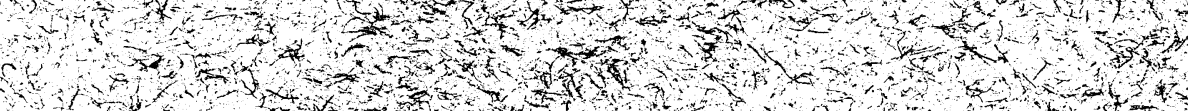

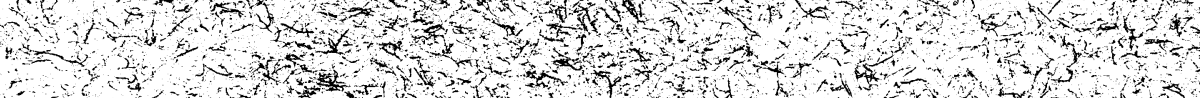

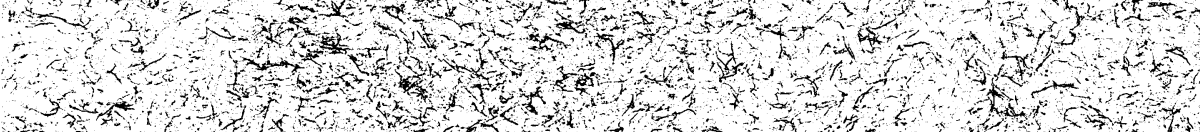

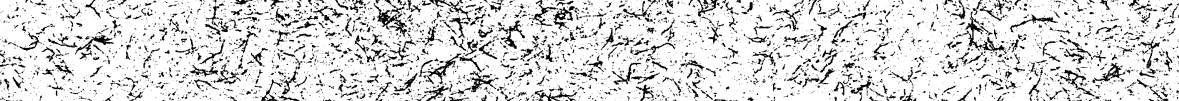

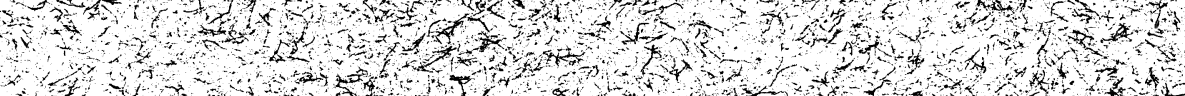

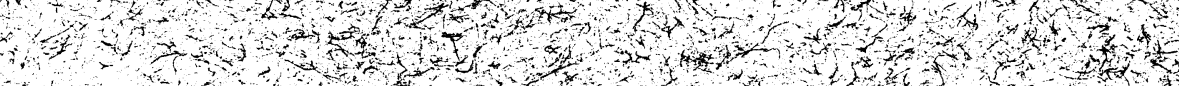

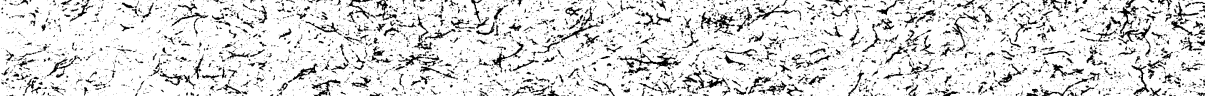

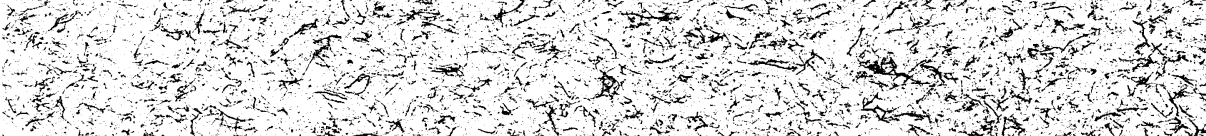

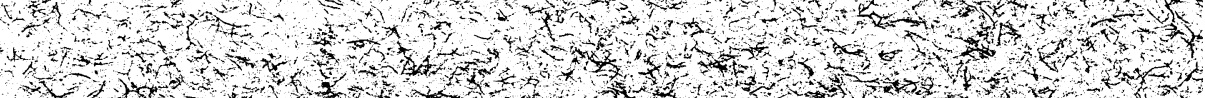

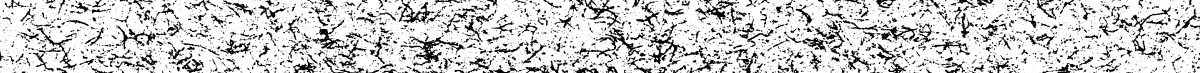

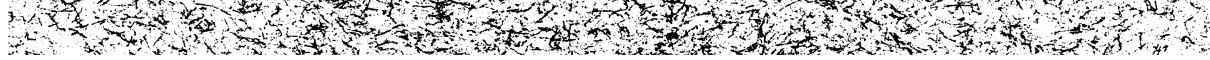




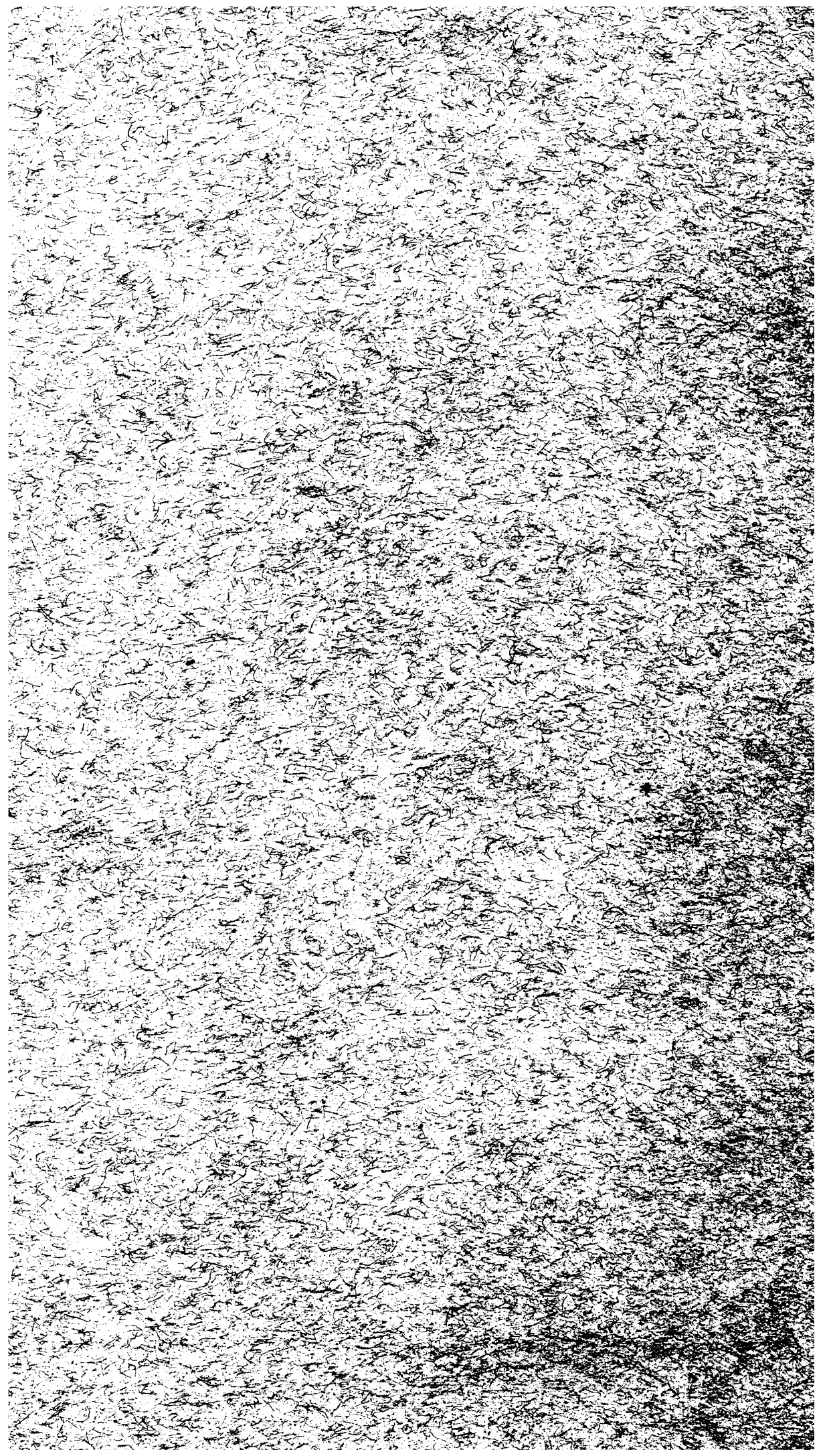

